\title{
Migration and Integration: A Dilemma in the Integration of Afghan Refugees in Relation to Crimes in Khyber Pakhtunkhwa
}

\author{
W. Khan (Wassem Khan), J. Khan (Jamil Khan), M. Humayun (Muhammad \\ Humayun), A. Naz (Arab Naz)
}

University of Malakand, Pakistan.

\section{E-mail address:}

arab_naz@yahoo.com

\section{Reprint address:}

Arab Naz

University of Malakand

Faculty of Social Siences

Khyber Pakhtunkhwa

Pakistan

Source: Clinical Social Work and Health Intervention

Volume: 11

Issue: 4

Pages: $14-22$

Cited references: 32

\section{Reviewers:}

Roberto Cauda

Institute of Infectious Diseases, Catholic University of the Sacred Heart, Rome, Italy

Gabriela Lezcano

University of California, San Francisco, USA

\section{Keywords:}

Migration. Afghans. Refugees. Integration. Settlement. Job Market. Illegalities.

\section{Publisher:}

International Society of Applied Preventive Medicine i-gap

CSWHI 2020; 11(4): 14 -22; DOI: 10.22359/cswhi_11_4_02 (C Clinical Social Work and Health Intervention

\section{Abstract:}

Migration is a universal phenomenon that has presence since human existed on earth. People move from one place to another having a variety of purposes, where the most common and dominant reasons are compulsions and inadequacy of resources to fulfill life needs at the country of origin. The current study is an attempt to understand the phenomenon of migration especially Afghan refugees residing for more than three decades in the KP province of Pakistan. The research work is part of a PhD study on migration and criminality which asserts on the associated parameters with migration that lead to unhealthy activities in the host society. The study is framed under qualitative 
research design utilizing the qualitative tools for data collection and thematic analysis in three major Divisions i.e. Peshawar, Mardan and Malakand of the province. The central and district jails were selected for identification of respondents and conduction of interviews to dig out the actual facts. The study concludes that unstable socio-political structure of the society diminishes the provision of basic rights to the Afghan refugees where the local masses consider them a threat to their socioeconomic, cultural and political existence. On the contrary, the Afghan refugees become expressive and reactionary and develop feelings of inferiority and deprivation when not given with the expected demands that lead to their mal-integration and mal-social-practices for their survival, integration and settlement.

\section{Background of the Study}

People move from one place to another to fulfill their basic needs of life. In order to transgress borders, these movements are defined as international migration and treated with great concerns in receiving societies. The persons living for a period of one year outside their countries of origin are considered as international migrants, which are estimated as 214 million (in 2008) including labor force, refugees, asylum seekers, students and professionals in various fields constituting $3 \%$ of the total world population (Koser 2010).

Migration being an international phenomenon has given rise to a debate on multiculturalism and ethnic diversification where the people at the receiving end consider such movement a threat to their respective identities (Synder 2011). Research studies and official records emphasize that migration might be both 'voluntary' and 'involuntary' (Ministry of Foreign Affairs 2001), which is most often caused by political unrest, socioeconomic problems and insecurity in the underdeveloped countries. In addition, the emergence of globalization has strengthened such movement in terms of proactive as well as reactive migration (Richmond 1994).

Being a controversial and highly debated phenomenon, migration entails (both) productive and destructive repercussion on countries of (both) the origin and receiving of the mover. At their initial entry to the receiving country, the international migrants are faced with a number of issues ranging from their food and shelter to getting citizenship. It is generally understood that people moving from one place (especially their origin) to another (mostly destination and nonnative) face hardships in their (re)settlement and adjustment.

In such a flow of hardship, the most common and foremost constrained object of their lives is their integration in the host society. Upon arrival into the host society, they come in conflict with a new culture and challenge the parental attitudes, behaviors, authorities and perceptions (Choudhry, Jandu, Mahal, Singh, Sohi-Pabla, Mutta 2002; Michel, 2004). As a result, the migrants get traumatized and caught in "bicultural expectations" (Segalm, Mayadas 2005). Most often, they are either less-integrated or disintegrated because of no family support and stability"; socio-economic networks; language proficiency; interpersonal skills; personal resilience (Carter, Polevnychok, Friesen, \& Osborne 2008; Enns, 2008; MacKay, Tavares, 2005; Murdie 2008). Among these, the significant issue that the migrants are faced with is the receiving of education. They face difficulties in getting formal education as most of them do not inherit literary skills and a good academic background from their countries of origin (Rossiter; Rossiter 2009). Apart from education, migrants also face health problems during and on their arrival into the host societies. During their travel they are faced with poor health services including malnutrition, lack of access to proper health care services, and overcrowded camps (situated at both the sending and receiving societies) (Pavli, Maltezou 2017).

These parameters (along with dozens more) shake their social life with miseries. The diversity 
in their settlement, the vulnerability of domestic workers and emerging trends of xenophobia add to already unfavorable scenarios and make them worse. The situation even becomes more exacerbated when these challenges lead them to indulge in illegal activities for their survival and existence. They lose the social capital and become involved in crimes, violence and gang activities (Gordon, 2000; Wortley, 2003; Wortley, Tanner 2007).

\section{The Argument}

Migrants face problems almost everywhere on their arrival that mainly correspond to the issues of their reception and socio-economic adjustment/resettlement in host societies (Menvis 2010). Initially, they make their demands for water, food, housing, education, health services, sanitation and transportation, and in some cases for natural resources such as grazing and firewood (World Bank Report, 2011).

Migrants also bring with them some expectations into the host communities. They aspire for a job or a source for earning which is most often not favorable. They usually fail to properly assess the situation in labor market because most of them do not permit migrants due the overwhelming labor market, youth bulge, limited vacancies and government restrictions (Oucho, Williams 2005). With the migrant-status, in many countries they are usually not allowed to work, which diverts them towards illegal mechanisms and thus indulge in criminality (Menjívar, Lakhani 2016).

Relationally, the problems in accommodation usually force them to settle in slums. The infrastructure that exists such as sewage, water supply, medical services and sanitation services are badly affected so when they are settled in such areas that do not meet the required standard of life (Mberu, Ezeh, Chepngeno-Langat, Kimani, Oti 2013), which creates a sense of deprivation, inferiority and frustration among them to think negatively and engage illegality.

The slum-based-settlement paves the way for a new culture of miseries and vulnerabilities which compels the migrants to adopt a short way out that is more likely to be illegal. These illegalities (crimes) to which migrants are most frequently related are non-violent. In this context, the crimes data indicates that in migrants the most widely spread crimes are counterfeiting, crimes against property (shoplifting or snatching, petty thefts) along-with in some instances the committing of violent crimes. Data concerning homicides show that the committing of the one third killings in the host communities is related to migrants (Savona, 1996). Migrants are also involved in crimes like drug abuse and trafficking, and violation of immigration laws in host communities. In response, the legal system instills punishments on migrants that are most often stricter than given to the natives for same misconducts. Resultantly, the migrants create a feeling of hatred and revolt for natives that further lead to the commission of expressive (violent) crimes in the host community (Savona, 1996).

The facts mentioned above might be elaborated in relative perspective in terms of the status of the receiving country. It is factually understood that the facilitation of migrants in stable and unstable countries must be different. A migrant entering to a developed country (first world) will be entertained appropriately while will be treated differently in the states that are suffering from instability (Third World). Similarly, Pakistan as a Third World country (suffering from economic, political, sectarian, educational etc. challenges) has received an alarming number of Afghan refugees since the Soviet occupation of Afghanistan in 1979.

Based on these facts, the integration of Afghan refugees in Pakistan is at the verge of deprivation and destitution. The country has witnessed almost 3 million refugees in 2017, which shows a significant number of Afghans in Pakistan (Khan 2017). The situation has been worsened when dire needs of the arriving population are not properly met and managed. They have struggled (and are still struggling) a long way for their existence, integration and survival in many aspects. Among these, the illegal way has been predominantly adopted when added by the diversity in their settlement, the vulnerability of domestic workers and proliferation of xenophobia among the arriving masses.

\section{Objectives of the Study}

The current study is based on a broad objective i.e. 'investigation of the socio-economic problems in integration of Afghan refugees in relation to their involvement in crimes in Khyber Pakhtunkhwa'. In this context, two major indica- 
tors have been identified, which play a dominant role in worsening the issue of their integration, which in-turn, lead them to adopt criminal and illegal ways for their settlement, integration and/or survival or existence. These objectives are:

To highlight the role of diversity in refugees' settlement in their mal-integration and criminal conducts

To investigate the vulnerability of domestic workers with a tendency to defective integration and criminality of Afghan refugees in the area

\section{Plan of Work/Methodology: Nature and Locale of the Study}

The study is framed under qualitative research design to assess and investigate subjects' (Afghan refugees') behaviors in terms of their integration and diversion/adoption to illegal means for survival and existence. The study is conducted in Khyber Pakhtunkhwa Province where the three major Divisions i.e. Peshawar (Central Jail Peshawar); Mardan (High Security Prison); Malakand (District Jail Malakand) are selected for study.

\section{Samples, Sampling Technique, Data Collection and Analysis}

The samples were conveniently selected from the mentioned jails qualifying the 4-point criterion i.e. (1) Afghan refugee, (2) a male, (3) above 18 years of age and (4) convicted for crime(s). Based on this, a total of 80 samples were selected and interviewed through an interview guide while the responses were recorded both on paper and audio recorder. In addition, three (03) Focus Group Discussions were also conducted with the subject respondents, where case studies and observation methods were also applied when deemed necessary. The collected data is thematically analyzed in terms of translation, transcription and narration to unfold the facts as below:

\section{Diversity of Refugees' Settlement}

The resettlement process varies from group to group and context to context. It is neither a particular group nor a segment in society that faces difficulties in resettlement but also becomes difficult to resettle with in one's own ethnic group. Different researchers have reflected with different typologies of refugees' resettlement.
Colic-Peisker and Tilbury (2003) while working with Bosnian refugees in Australia argue that the refugees inheriting resources are likely to be easily settled. On the contrary, refugees characterized as 'endurers' and 'victims', who face multiple challenges of being forced to leave for resettlement in countries and communities in a vastly different social environment. Consequently, they suffer from mental health issues during their refuge and are likely to adopt a 'passive' approach to resettlement and will relatively live in social isolation and distance not only from the mainstream society, but also their ,ethnic community“ (Colic-Peisker, Tilbury 2003).

The ability to successfully resettle in receiving societies also depends on cultural distance, the displacement experience, and resilience of individuals in overcoming difficulties. However, it is argued that refugees should have access to a labor market. Keeping them out of labor markets will create a sense of deprivation, distress and tension and hinder their social integration and increase poverty (McColl et al. 2008). In this context, the empirical data asserts as

„We are peacefully living in our neighborhood and want to live with our community. They (the locals) call upon us and taunt us as 'kala ba zey (when will you leave)', 'mahajara ao da khrey jajara, dera khurey ao dera obasey (Oh migrant, you are the magazine (to be read as a weapon's magazine) of donkey, you eat more and then pee more', 'kabaliya khpal watan ta za kana halalom dy' (Oh man of Kabul, move back or I'll slaughter you) (An Afghan child expressed his feeling) we live away from them so we have not learnt anything from them."

„We cannot live with the locals because we are large in size (the family size), and unable to rent a house because they are expensive. We are also different from each other in terms of solemnizing our marriages as well as festivals. Your (locals) marriages are too expensive, and we are unable to do so, for example you give two- or three-times meal in a marriage and we provide only once. We are compelled to adopt the illegal means and earn illegally, because we don't have any support other than we offer labor. I was working with another Afghani (a cloth seller) and I stole some cloth to sell and earn. He caught me battered me so ferociously to make me insane 
and senseless. I'll do it again, because I have eight sisters and I am the only earner in the family. How can a person keep such a large family on daily wages, which is less than five hundred rupees a day?

Presently, I am not in a position to do any harm to others, but if I come into power, I'll behead and slaughter all Pakistanis, because I abhor them extremely. They are so cruel to us that they hadn't yet accepted us as humans. We are dealt inhumanly in Police stations, courts and by general public. I am powerless, because the law deals us differently here. We have to provide three Pakistani guarantors if arrested by police. Pakistanis are not accepting us as humans, so from where shall I find three men to offer my bail and become a guarantor. This discriminatory attitude is making me furious and hateful toward these people, which compels me to adopt the criminal and violent methods for survival.“

\section{Analysis and Discussion}

Settlement of strangers has always been an issue in the entire world. Migrants almost in all parts of the world are supposed to be strangers and outsiders. With the passage of time, they become so resembled with the host community that they consider themselves as insiders. Same is the case with Afghan refugees in Pakistan, where initially they intended to find only a shelter to live, while after spending decades, they are engulfed in local community to such an extent where their disapproval leads to disruption.

The empirical information also points to such fact that they have developed a long range of expectation in the local community. In addition, they are more associated in Khyber Pakhtunkhwa province because of lingual and cultural similarities in both the segments. In this context, the problem arises when the local community denies their equality and deals them absurdly which in most instances is not tolerated by the Afghans. The locals expect that they should be grateful, submissive and passionate towards few of the discriminatory practices in return of the benefits they are given with in such limited resources. Here the locals are confronting issues of poverty, unemployment, health services and education, etc. but still they have accommodated the huge burden of Afghans who (according to locals) are occupying the market and scarce availability of jobs. Such a conflict of interests and expectations lead both the communities into conflicting situations and force the strangers to adopt the rebellious way for meeting their needs and integration. The primary data thus explicitly depicts that the intolerance of the locals makes the non-locals intolerants and compel them to integrate by force and settle in an unplanned manner which most often ends in violence and resumes in hatred.

\section{Vulnerability of Domestic Workers}

Refugees work both in formal and informal economies. However, the most available work is the household cleaning and childcare. Women are serving in homes and most of men are likely to find employment in the service sector working as chaueffeurs, deliverymen or gardeners. Refugee workers are also discriminated in terms of wages as compared to the local workers. It is also believed that refugees working as domestic workers are not protected by labor laws. Jureideni's (2009) study indicates that $10 \%$ of the respondents complained that they have been victims to sexual assaults, including rape, inappropriate touching and sexual demand and are fired when refusing such demands. As a result, many refugees are jobless in the local markets. Under such circumstances, refugees get insecure, deprived, frustrated and reported to resort to alternative means to fulfill their needs. Response from the local Afghan migrants reported in the following manner:

„I had to work for 5 rupees of wages. The wage level was higher in the market for the locals i.e. Rs.12. We did not fight for our wage with the local, the reason was we were poor and Afghans. I also managed for my home with the help of locals with whom I had come in contact. There was a hell of a difference. You (indicates himself, to be read as 'I') cannot tell your relatives that you were working as a laborer in Pakistan once you go back. The jobs we are offered in Pakistan are so cheap and menial that we feel ashamed of doing them, but we have to do them for our survival, otherwise we'll die of hunger. Such contemptuous treatment makes us frustrated and feeling to revolt arises from inside."

We (means I - original extracts reflect the word 'we') are working with Pakistani. We have 
no such problems with Pakistanis besides wages. Pakistanis are preferred on Afghanis; it is because of the threats and no jan pehchan (understanding and identity). We are paid less and late; Pakistanis are paid more and in-time; this is the only difference we are faced with. Now can you tell me, what is the extent of this discrimination - either minor or major?

In this context, market liberalization also causes deprivation, social unrest and disruptive behavior (Haruna 2015). The unequal status of the labor market is not only responsible for the poor economic performance but also affects social behavior which creates a sense of distrust and frustration among individuals leading them to crimes. In addition, Becker (1968) has argued on the link of income inequality with committing of crimes. He says that crimes would be committed if the potential benefits of illegal acts are greater than the costs of apprehensions. Thus, people resort to commit criminal behavior when it pays more than a job in labor market.

However, without the right to work, research works reveal that refugees seek a wide range of means to generate alternative income. These strategies are revealed to be used by both the natives and refugees (Lewis 2007). Crawley et al., (2011) have also recorded that few women and men have been resorted to engage in some irregular working as sex workers.

„I am taking ice (the methamphetamine drug). I enjoy sex when I am in habit of taking ice. Those who are rich will enjoy it most (with high laughter). I cannot say exactly but $20 \%$ of the whole society is involved in sexual relations. I am doing sex for taking satisfaction. You cannot imagine that how much money I can earn from such acts. I will not stop from doing such acts because we require a lot of money to fulfill our needs."

However, the studies independently note the involvement in crimes being the only strategy for survival. A survey conducted by Querton (2012) revealed that several women were found involved in sex works as means of their survival. While Phillimore and Goodson (2010) depict that since the women are susceptible to sexual abuse, their involvement in sex work is not attributed to the income resources but to other exchanges as well, such as accommodation. While on the other hand, men are more able to seek and resort to in- formal employment. The involvement in the informal economy is likely to be more prominent in refugees who are refused being asylum seekers (Taylor, 2009).

„I was working with a Pakistani for the last 20 years. He did not know that I was an Afghani but came to know when I took his money. I used to bring cars from other parts of the country. He had developed trust in me and even he never hesitated to transfer/transact money. One day he asked me to go to the bank and bring money. It was about one million rupees and I had not seen such a huge amount in my life. I took the money and absconded from the scene. I was arrested by police in Lahore brought to court. I confessed my crime and was imprisoned for seven years. I had thought that is better to take a huge money which I had in hand than I could earn in half a century.“

\section{Analysis and Discussion}

The third world has long been confronted with dozens of malpractices: the social structure is distorted; the economic structure is unable to hold the standard of life; the political institution is not capable of bringing order in society which brings adversity in social life. In such scenarios, the advent of strangers to such a community and in such a large proportion in no time worsens the situation. The literary and empirical discussion asserts that Pakistan and Afghanistan are no way structurally and administratively dissimilar. Although there might be a difference in their progress, Pakistan with such a huge population is still struggling to provide medium level life standards to its masses. In the meanwhile, the arrival of vast Afghan refugees was an unbearable responsibility for Pakistani society. In such conditions, both the parties (Paki and Afghani) are in the right. Being similar in terms of culture, language and religion, the Afghan migrants consider themselves rightful of being treated with respect, honor and equality, while contrary to this, the Pakistanis are complaining of this wrong decision to encompass more than 3 million extra population. The KP province particularly has been most vulnerable in this context, where domestic workers are deprived of the already scarce opportunities for jobs. On the other hand, the complaint of Afghanis might be acceptable that they are 
treated beyond discrimination. Even human rights are also not available to them which compel them to indulge in unhealthy and criminal conducts. Thus, saturation of the job market results in scarcity of employment. Afghans offer jobs at low wages, where the self-esteem of locals has been threatened. They either remain jobless or come into confrontation with Afghanis to snatch their rights back.

\section{Conclusion}

Transgression of borders through people's migrations from one place to another is a certified fact. It is either a need of people to move; a compulsion to meet some needs; to avoid some unpleasant threat. Such movements take place in dynamic situations which yield diverse results depending on the purpose of movement; the socio-cultural and economic and political conditions of both the countries (origin and destination); the socio-economic status of the mover.

The fact is evident that the movement that takes place in compulsion because of the sociopolitical and structural unrest in the countries of origin yields unpleasant results in the host countries. The immigrants are usually not welcomed, rather they enter the country either by force, or solicitation or illegally. All these parameters for movement of people are unwelcoming, which in turn put the immigrants into another challenging scenario to face. Both the local masses and governments do not let them live freely and rarely accept them being ordinary citizens having all rights and privileges.

Similarly, the current study has intended to identify the factors that restrict the integration and settlement of Afghan refugees in KP province. These migrants, although residing for more than 3 decades, are still faced with discriminatory practices and are yet to be accepted as general masses. These refugees are considered special masses who in the name special care, are dealt in special circumstances. The study found multiple reasons that these people confront in their of settlement and integration. The most deeply engraved parameter is the instability of Pakistani socio-political structure. The exponentially higher population of the country is living below standardized minimums of life combating with issues of destitution, joblessness, insufficient health services, security problems and ex- tremism. In such scenarios, the advent of more than 3 million extra population in extremely pathetic conditions, was never easy for such a country which has been and is struggling hard to fulfill basic needs of its masses.

Consequently, issues emerged in settlement of these refugees as they were kept in isolation in the form of camps. This isolation created a distance between the locals and the migrants because there was a clash of expectation between both the parties. The migrants were expecting a welcoming and respectful approach, while the locals considered them as a burden and invaders on the already devastated economy and a threat to the scarcely available income resources. After spending several decades, they are still considered outsiders and kept at distance, which is no more acceptable to the migrants these days. This conflict of thoughts based on economic resources and settlement issues, led the outsiders to think differently and adopt some other ways to find solution. In this context, the rational choice approach of criminal studies was justified, that the Afghan refugees adopted the illegal ways to integrate themselves, which gave birth to a new kind of conflict between the arrivers and the receivers in terms of adjustment, integration, settlement and job market. The study reveals that the continuation of such struggle between both segments might result into actual conflict (which in many instances has taken place) and might lead to a new argument of forceful settlement of these refugees.

\section{References:}

1. BECKER GS (1968) Crime and punishment: An economic approach. Journal of Political Economy, Vol. 76 (2), pp. 169-217.

2. CARTER T, POLEVYCHOK C, FRIESEN, A, OSBORNE J (2008) The housing circumstances of recently arrived refugees: The Winnipeg Experience. Report presented to the Prairie Metropolis Center, Edmonton, AB. Retrieved on February 21, 2019, from http://pcerii.metropolis.net/frameset_e.html

3. CHOUDHRY UK, JANDU S, MAHAL J, SINGH R, SOHI-PABLA H, MUTTA B (2002) Health promotion and participatory action research with South Asian women. Journal of Nursing Scholarship, Vol. 34 (1), pp. 75-81. 
4. COLIC-PEISKER V, TILBURY F (2003) Active and passive resettlement: The influence of support services and refugees' own resources on resettlement style, International Migration, Vol.41 (5), pp.61-92.

5. CRAWLEY H, HEMMINGS J, PRICE N (2011) Coping with Destitution: Survival and Livelihood Strategies of Refused Asylum Seekers Living in the UK. Swansea: Centre for Migration Policy Research (CMPR).

6. ENNS R (2008). Recent housing experiences of immigrants in Winnipeg, Edmonton, and Calgary. Paper presented at the Prairie Metropolis Centre, Edmonton Research Symposium, Edmonton, AB, Canada.

7. GORDON (2000) Criminal business organizations, street gangs and 'wanna-be' groups: A Vancouver perspective. Canadian Journal of Criminology, Vol. 42 (1), pp. 39-60.

8. HARUNAA (2015) Joblessness and the State Policy on Violent Crime: Impacts of Motorcycles Banning In Damaturu Yobe State, Nigeria. International Journal of Advanced Research in Management and Social Science, Vol. 4 (10), pp. 152-168.

9. JUREIDINI R (2009) Irregular Workers in Egypt: Migrant and Refugee Domestic Workers. International Journal on Multicultural Societies, Vol. 11(1), pp. 75-90.

10. KHAN A (2017) Afghan Refugees in Pakistan. Institute of Strategic Studies.

11. KOSER K (2010) Introduction: International Migration and Global Governance, Global governance, Vol. 16 (3), pp. 301-315.

12. LEWIS H (2007) Destitution in Leeds: The Experiences of People Seeking Asylum and Supporting Agencies. Yorkshire, Joseph Rowntree Charitable Trust.

13. MACKAY T, TAVARES T (2005) Building hope: Appropriate programming for adolescent and young adult newcomers of war-affected backgrounds and Manitoba Schools. Winnipeg, MB: Manitoba Education, Citizenship and Youth.

14. MBERU BU, EZEH AC, CHEPNGENO LANGAT G, KIMANI J, OTI S (2013) Family ties and urban-rural linkages among older migrants in Nairobi informal settlements. Population, Space and Place, Vol. 19 (3), pp. 275-293.

15. MCCOLL $\mathrm{H}$, MCKENZIE $\mathrm{K}$, BHUI $\mathrm{K}$
(2008) Mental healthcare of asylum-seekers and refugees, Advances in Psychiatric Treatment, Vol.14 (6), pp. 452-459.

16. MENJIVAR C, LAKHANI S M (2016) Transformative Effects of Immigration Law: Immigrants' Personal and Social Metamorphoses through Regularization. American Journal of Sociology, Vol. 121 (6), pp. 18181855.

17. MENVIS B (2010) Inside the Kebab Shop \& Outside of Society; Turkish immigrants working in fast food sector in Sweden and their Integration. MA Thesis, Department of Social Work, Gothenburg University. Retrieved on March 6, 2019, from https://gupea. ub.gu.se/bitstream/2077/25311/1/gupea_207 7_25311_1.pdf

18. MICHEL J (2004) Identity development of young women from Haitian immigrant families in the United States: A qualitative exploratory study. Dissertation Abstracts International. Section B: The Physical Sciences \& Engineering, 64, 9B (UMI No. 4626).

19. MURDIE RA (2008) Pathways to housing: The experiences of sponsored refugees and refugee claimants in accessing permanent housing in Toronto. Journal of International Migration and Integration, Vol. 9 (1), pp. 81101.

20. OUCHO AL, Williams AD (2005) Challenges and solutions to migrant integration, diversity and social cohesion in Africa. African Migration and Development Policy Centre.

21. PAVLI A, MALTEZOU H (2017) Health problems of newly arrived migrants and refugees in Europe, Journal of Travel Medicine, Vol. 24 (4), pp. 1-8.

22. PHILLIMORE J, GOODSON L (2010) Failing to adapt: institutional barriers to RCOs engagement in transformation of social welfare, Social Policy and Society, Vol. 9(2), pp. $1-12$.

23. QUERTON C (2012) I Feel like as a Woman I'm not Welcome: A Gender Analysis of UK Asylum Law, Policy and Practice. London, Asylum Aid.

24. RICHMOND A (1994) Global Apartheid: Refugees, Racism and the New World Order. Toronto: Oxford.

25. ROSSITER JM, ROSSITER RK (2009). Im- 
migrant youth and crime: Stakeholder perspectives on risk and protective factors, Working Paper No. WP02-09, PMC Working Paper Series, Prairie Metropolis Centre.

26. SAVONA EU (1996) Dynamics of migration and crime in Europe: new patterns of an old nexus, Research group on transnational Crime, Working Paper No.8, University of Trento, School of Law.

27. SEGAL A, MAYADAS SN (2005) Assessment of Issues Facing Immigrant and Refugee Families. Child Welfare League of America, Vol. 5, pp. 563-583.

28. SYNDER S (2011) Encountering Asylum seekers: An Ethic of Fear or Faith? Studies in Christian Ethics, Vol. 24 (3), pp. 350-366.

29. TAYLOR D (2009) Underground Lives: An Investigation into the Living Conditions and Survival Strategies of Destitute Asylum Seekers in the UK. Leeds: PAFRAS.

30. WORLD BANK REPORT (2011) The Impacts of Refugees on Neighboring Countries: A Development Challenge. World Bank.

31. WORTLEY S (2003) Hidden intersections: Research on race, crime and criminal justice in Canada. Canadian Ethnic Studies Journal, Vol. 35, pp. 99-117.

32. WORTLEY S, TANNER J (2007) Criminal organizations or social groups? An exploration of the myths and realities of youth gangs in Toronto (first draft). University of Toronto. Retrieved on February 14, 2019, from http:// ceris.metropolis.net/Virtual\%20Library/EResources/WortleyTanner2007.pdf. 